\title{
Large plasticity induced crack initiation from $U$-notches in thin aluminum sheets under mixed mode loading
}

\author{
A. R. Torabi* and B. Mohammad Hosseini
}

\begin{tabular}{|c|c|}
\hline A R T I C L EI N F O & A B S T R A C T \\
\hline $\begin{array}{l}\text { Article history: } \\
\text { Received } 6 \text { July, } 2016 \\
\text { Accepted } 2 \text { October } 2016 \\
\text { Available online } \\
\text { 3 October } 2016 \\
\text { Keywords: } \\
\text { Load-carrying capacity } \\
\text { Equivalent Material Concept } \\
\text { Ductile failure } \\
\text { U-notch } \\
\text { Abrupt fracture } \\
\text { Mixed mode I/II loading }\end{array}$ & $\begin{array}{l}\text { Ductile failure is investigated experimentally and theoretically in U-notched Al 7075- T6 thin } \\
\text { sheets under mixed mode I/II loading. First, several U-notched rectangular sheets are subjected } \\
\text { to mixed mode I/II failure tests and the load-carrying capacity of the sheets are experimentally } \\
\text { recorded. Then, the Equivalent Material Concept (EMC) is employed in conjunction with the } \\
\text { U-notch maximum tangential stress (UMTS) and U-notch mean stress (UMS) criteria to } \\
\text { theoretically estimate the load-carrying capacity of the U-notched Al 7075-T6 sheets. It is } \\
\text { shown that the experimental failure loads are well predicted by means of both the UMTS-EMC } \\
\text { and UMS-EMC criteria. Moreover, the experimental observations and the elastic-plastic finite } \\
\text { element analyses indicate that the U-notched aluminum sheets fail by the large-scale yielding } \\
\text { (LSY) regime. }\end{array}$ \\
\hline
\end{tabular}

\section{Nomenclature}

$d_{c} \quad$ Critical distance of the UMS criterion measured from the notch tip

$d_{c, U} \quad$ Critical distance of the UMS criterion measured from the coordinate origin

E $\quad$ Elastic modulus

$K \quad$ Strain-hardening coefficient

$K_{I}^{U, \rho} \quad$ Mode I notch stress intensity factor (NSIF) for a U-notch

$K_{I I}^{U, \rho} \quad$ Mode II notch stress intensity factor (NSIF) for a U-notch

$K_{I c}^{U, \rho} \quad$ Mode I notch fracture toughness for a U-notch

$K_{c} \quad$ Fracture toughness of material

\footnotetext{
* Corresponding author. Tel: +98-21-61118572, Fax: +98-21-88497324

E-mail addresses: a torabi@ut.ac.ir (A. R. Torabi) 
$K_{I c} \quad$ Plane-strain fracture toughness of material

UMS U-notch mean-stress

UMTS U-notch maximum tangential stress

$n \quad$ Strain-hardening exponent

$r_{c} \quad$ Critical distance of the UMTS criterion measured from the notch tip

$r_{c, U} \quad$ Critical distance of the UMTS criterion measured from the coordinate origin

$r_{0} \quad$ Distance between the coordinate origin and the notch tip

$\beta \quad$ Notch rotation angle

$\varepsilon_{f}^{*} \quad$ Strain at crack initiation for the equivalent material

$\varepsilon_{p} \quad$ True plastic strain

$\varepsilon_{u} \quad$ Engineering plastic strain at maximum load

$\varepsilon_{u, \text { true }} \quad$ True plastic strain at maximum load

$\varepsilon_{p}^{Y} \quad$ True plastic strain at yield point

$\varepsilon_{Y} \quad$ Elastic strain at yield point

$\rho \quad$ Notch radius

$\sigma \quad$ True stress

$\sigma \quad$ Critical stress

$\sigma_{f}^{*} \quad$ Tensile strength of the equivalent material

$\sigma_{r \theta} \quad$ In-plane shear stress

$\sigma_{\theta \theta} \quad$ Tangential stress

$\overline{\sigma_{\theta \theta}} \quad$ Mean value of tangential stress

$\sigma_{u} \quad$ Ultimate tensile strength

$\sigma_{Y} \quad$ Yield strength

\section{Introduction}

Although notches are normally fairer than sharp cracks, their fracture behavior can be similar or dissimilar to the behavior of cracks depending on the notch geometry and hence the stress concentration and the stress gradient at the notch vicinity. For significant stress gradients, fracture assessment based on the classic mechanics of materials, which uses the stress concentration factor (SCF) as the main parameter of the stress field, is no longer valid because it results in considerable errors. For such cases, the principles of the notch fracture mechanics (NFM), which utilize the notch stress intensity factors (NSIFs) as the governing failure parameters, should be used instead.

Indeed, cracks and notches are similar from the view point of the stress concentration; however, there is a great difference between them in definition of the fracture toughness. For a cracked member, the plane-strain fracture toughness is assumed to be a material property and denotes the ability of withstanding the material containing a pre-existing crack against crack propagation. However, for a component weakened by a notch, the notch fracture toughness (NFT) depends not only on the material properties, but also on the notch geometry. Physically, the NFT denotes the resistance of the notched member against crack initiation from the notch tip or border. For a notched member made of a brittle material, the crack initiation from the notch border is simultaneous with the final fracture because the 
crack propagation phase takes place in such a short time interval that it cannot be captured by the naked eye. However, for a notched member made of a ductile material obeying elastic-plastic behavior, as the load on the member increases, a plastic region normally nucleates from the notch border and develops in the ligament in small or large amount and finally, the crack initiates from the notch border for a specific load, called the load-carrying capacity (LCC) of the notched member. Depending on the total strain to failure and the strain at which the ultimate load is achieved, crack growth and final fracture can occur slowly or abruptly.

For ductile components containing cracks, four failure regimes can be recognized depending upon the size of the plastic zone around the crack tip at failure instance. They are the small-scale yielding (SSY), moderate-scale yielding (MSY), large-scale yielding (LSY) and the gross yielding (GY). For cracks encountering SSY, the fracture prediction is usually performed using the brittle fracture criteria in the context of the linear elastic fracture mechanics (LEFM) by ignoring the fracture energy absorbed by the small plastic zone around the crack tip. In SSY cases, it is also possible to slightly modify the brittle fracture criteria and utilize them in fracture predictions. For the other three regimes, the failure assessment by means of the brittle fracture criteria is not permissible and hence, the elastic-plastic failure criteria, e.g. the critical J-integral, the resistance curve (R-curve) etc., should be employed (Anderson, 1995; Saxena, 1998). Like for cracks, the use of the principles of the linear elastic notch fracture mechanics (LENFM) for fracture analysis of notched ductile components encountering significant plasticity at the notch vicinity is not allowable and thus, the elastic-plastic notch fracture mechanics (EPNFM) principles, which are complex and time-consuming, should be used.

The first ones who utilized the LENFM for predicting failure of notched ductile components were probably Susmel and Taylor (2008a). They applied the Theory of Critical Distances (TCD) (Taylor, 2008; Susmel \& Taylor, 2008b) to the linear elastic stress field around notches of various shapes and estimated well the load-carrying capacity (LCC) of notched plates made of very ductile commercial steel and subjected to mode I loading (i.e. the opening mode) (Susmel \& Taylor, 2008a). It has been shown by Susmel and Taylor (2008a) that the linear elastic TCD is surprisingly successful in crack initiation prediction of notched steel plates encountering LSY failure regime. By Torabi (2012), the success of the linear elastic TCD reported by Susmel and Taylor (2008a) has been attributed to the close values of the yield and ultimate tensile strengths of the commercial steel. Torabi (2012) proposed originally the Equivalent Material Concept (EMC), by which a ductile material having valid fracture toughness $K_{I c}$ value is equated with a virtual brittle material having the same elastic modulus and fracture toughness but different tensile strength, in order to overcome the restrictions of the valuable TCD analysis carried out by Susmel and Taylor (2008a). By linking EMC to the two stress-based brittle fracture criteria, namely the point-stress (PS) and mean-stress (MS) criteria, Torabi (2012, 2013a, $2013 b$ ) could successfully predict the experimental elastic-plastic failure results reported by Susmel \& Taylor (2008a) regarding the tensile LCC of the notched specimens. In an applied work published by Torabi (2013c), the success of the combined MS-EMC criterion in predicting the tensile LCC of ductile steel bolts containing $\mathrm{V}$-shaped threads was also demonstrated. Because the applicability of EMC does not depend on the level of material ductility, it is expected that it can be used for failure prediction of notched ductile components disregarding the type of ductile failure regime (i.e. MSY, LSY and GY). Moreover, because EMC acts as a bridge between the linear elastic and elastic-plastic analyses, it is expected that it can basically be linked to various brittle fracture criteria, e.g. the maximum tangential stress (MTS) and mean stress (MS) (Ayatollahi \& Torabi, 2010a, 2010b, 2011; Torabi, 2013d; Ayatollahi et al., 2011a, 2011b; Aliha \& Ayatollahi 2013; Mirsayar et al. 2014; Torabi et al., 2013, 2014c, 2014d; Torabi \& Amininejad, 2015a, 2015b; Torabi \& Pirhadi 2015; Torabi \& Abedinasab, 2015a, 2015b) criteria, the averaged strain energy density (ASED) criterion (Lazzarin \& Zambardi, 2001; Berto \& Lazzarin, 2014; Torabi \& Berto, 2014a; Torabi et al., 2014a, 2014b, 2015a, 2015b, 2015c; Ayatollahi et al., 2011; Berto \& Barati, 2011; Gomez et al., 2007, 2009a, 2009b; Berto et al., 2007, 2012; Berto \& Ayatollahi, 2011; Torabi \& Berto, 2014b, 2014c; Berto \& Lazzarin, 2009; Aliha et al. 2016), the cohesive zone model (CZM) (Gomez et al., 2000, 2006; Gomez \& Elices, 2003; Cendon 
et al., 2015) and the finite fracture mechanics (FFM) (Sapora et al., 2013, 2015; Cornetti et al., 2012, 2014; Weißgraeber \& Becker, 2013; Carpinteri et al., 2008) etc. under different in-plane loading conditions. Aluminum alloys are ductile materials that usually exhibit elastic-plastic behavior in standard tensile tests with significant strain to failure values. Due to the close values of the yield and tensile strengths of such materials, they have valid $K$-based fracture toughness $\left(K_{I c}\right.$ or $\left.K_{c}\right)$ values and hence, the fracture prediction of cracked and notched components made of aluminum alloys are normally performed by means of the failure criteria in the context of the LEFM. Recently, two research papers have been published in which the mode I notch fracture toughness (NFT) of Al 7075-T651 (Madrazo et al., 2012) and Al-Zn-Mg-Cu alloy (Vratnicaa et al., 2013) have been predicted by means of the brittle fracture criteria which are well-known in the LENFM context. While the predictions reported by Madrazo et al. (2012) and Vratnicaa et al. (2013) have been successful, it seems that the use of the LENFM criteria for such predictions is questionable because of existing significant plastic deformations around the notch at crack initiation instance. Similar restriction in failure prediction of notched ductile steel components by TCD was also explained above (Susmel \& Taylor, 2008a; Torabi, 2012).

More recently, Torabi and co-researchers have successfully utilized EMC to overcome the restrictions exist in failure prediction of notched members made of aluminum alloys by means of brittle fracture criteria. They made use of EMC in conjunction with two well-known stress-based brittle fracture criteria, namely the maximum tangential stress (MTS) and mean-stress (MS) criteria, to successfully predict the LCC of rectangular thin plates of Al 7075-T6 and Al 6061-T6 containing central U-notches under mode I loading (Torabi et al., 2015d), that of Al 6061-T6 containing inclined U-notches under mixed mode I/II loading (Torabi \& Habibi, 2015), and that of Al 7075-T6 containing inclined blunt V-notches under mixed mode I/II loading (Torabi \& Alaei, 2015).

In this research, first, failure of U-notched rectangular specimens made of Al 7075-T6 is experimentally investigated under mixed mode I/II loading conditions for different notch radii. The LCC of the specimens, which is achieved at the onset of crack initiation from the notch border, is experimentally recorded and the specimens after fracture are macroscopically analyzed for determining the type of failure. The inclined fracture surfaces demonstrate the ductile rupture of the specimens. Then, the experimentally recorded LCCs are predicted by using EMC in conjunction with the U-notch maximum tangential stress (UMTS) and the U-notch mean-stress (UMS) brittle fracture criteria. It is shown that the experimental results are successfully predicted by means of both the UMTS-EMC and UMS-EMC criteria under large-scale yielding conditions.

\section{Fracture experiments on U-notched Al 7075-T6 thin plates}

\subsection{Material}

The fracture experiments are performed on the aluminum alloy Al 7075-T6 which is known as a ductile material. Standard tests are carried out on the specimens to determine the mechanical properties of material. The tests are the tensile tests, the Poisson's ratio tests, and the fracture toughness tests for small thicknesses according to ASTM E8 (2013), ASTM E132-04 (2010), and ASTM B646-12 (2012), respectively. Fig. 1 shows the engineering and true stress-strain curves for the tested Al 7075-T6. The chemical composition and the mechanical properties of A1 7075-T6 are also presented in Tables 1 and 2 , respectively.

Table 1. Chemical composition of the tested Al 7075-T6

\begin{tabular}{|c|c|c|c|c|c|c|c|c|c|c|c|}
\hline Element & $\mathrm{Si}$ & $\mathrm{Fe}$ & $\mathrm{Cu}$ & $\mathrm{Mn}$ & $\mathrm{Mg}$ & $\mathrm{Zn}$ & $\mathrm{Ni}$ & $\mathrm{Cr}$ & $\mathrm{Pb}$ & $\mathrm{Sn}$ & $\mathrm{Ti}$ \\
\hline Weight (\%) & 0.06 & 0.32 & 1.72 & 0.03 & 2.44 & 4.63 & 0.004 & 0.2 & 0.002 & 0.001 & 0.037 \\
\hline Element & B & $\mathrm{Cd}$ & $\mathrm{Bi}$ & $\mathrm{Ca}$ & $\mathrm{P}$ & $\mathrm{Sb}$ & $\mathrm{V}$ & $\mathrm{Zr}$ & $\mathrm{Co}$ & $\mathrm{Li}$ & $\mathrm{Al}$ \\
\hline Weight (\%) & 0.001 & 0.001 & 0 & 0.001 & 0.001 & 0.001 & 0.007 & 0.017 & 0.003 & 0.001 & 90.5 \\
\hline
\end{tabular}




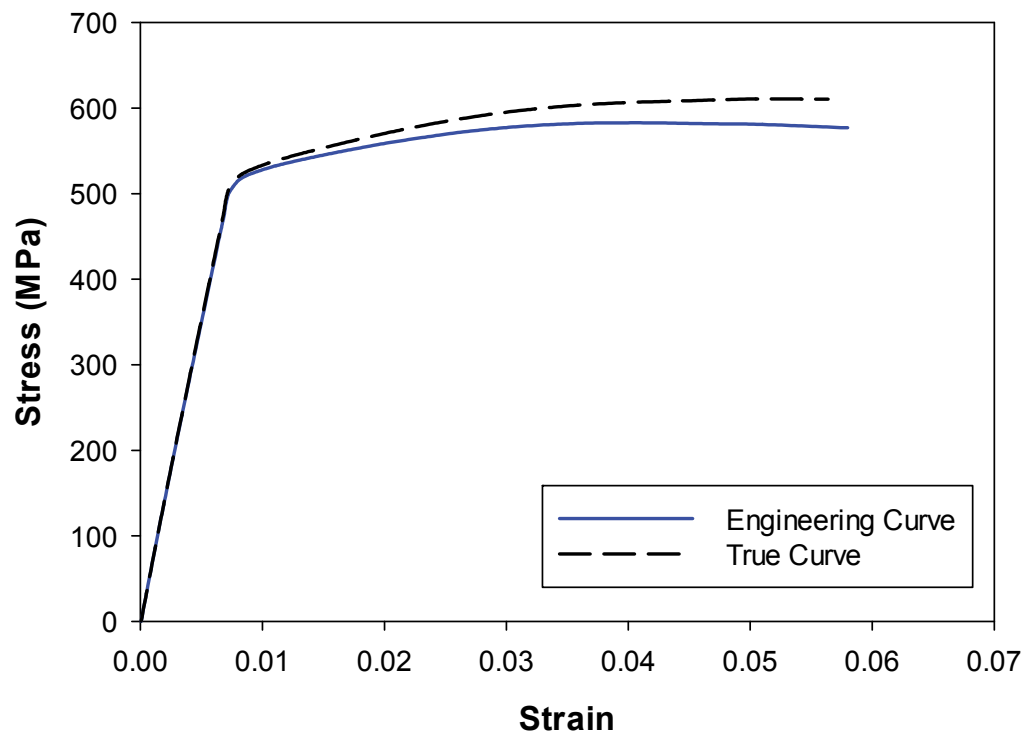

Fig. 1. The engineering and true stress-strain curves for the tested Al 7075-T6.

Table 2. Mechanical properties of the tested Al 7075-T6

\begin{tabular}{ll}
\hline Material Property & Value \\
\hline Elastic modulus, $E(\mathrm{GPa})$ & 71 \\
Poisson's ratio & 0.33 \\
Tensile yield strength $(\mathrm{MPa})$ & 521 \\
Ultimate tensile strength $(\mathrm{MPa})$ & 583 \\
\hline Elongation at break $(\%)$ & 5.8 \\
Engineering strain at maximum load & 0.047 \\
True fracture stress $(\mathrm{MPa})$ & 610 \\
Fracture toughness, $K_{c}(\mathrm{MPa} \sqrt{ } \mathrm{m})$ & 50 \\
Strain-hardening coefficient, $(\mathrm{MPa})$ & 698 \\
Strain-hardening exponent & 0.046 \\
\hline
\end{tabular}

\subsection{Test specimen}

Fig. 2 depicts the test specimen utilized in the failure experiments. The specimen is a rectangular thin plate containing a central bean-shaped slit with two U-shaped ends which is loaded under mixed mode I/II by applying a remote tensile load to the ends. The specimen is rotated counterclockwise by the angle $\beta$ with the aim to have combined tensile-shear deformations at the notch vicinity. The contribution of shear deformations increases as the angle $\beta$ enhances from zero (for $\beta=0$, the pure mode I loading is achieved), resulting in different mode mixity ratios.

In Fig. 2, the parameters $\rho, 2 \mathrm{a}, \mathrm{L}, \mathrm{W}, \beta$, and $\mathrm{P}$ denote the notch radius, twice the notch length (i.e. the total slit length), the specimen length, the specimen width, the notch rotation angle, and the remotely applied tensile load, respectively. The values of the parameters considered in the failure experiments are as follows: $\rho=0.5,1$ and $2 \mathrm{~mm} ; 2 \mathrm{a}=25 \mathrm{~mm} ; \mathrm{L}=160 \mathrm{~mm} ; \mathrm{W}=50 \mathrm{~mm} ; \beta=0,30$ and 60 (deg.). The thickness of the entire specimens is equal to $2 \mathrm{~mm}$. For each notch radius and rotation angle, three tests are carried out in order to examine the repeatability of the tests; all in all, 27 tests are performed in this experimental program. For preparing the specimens, first, an Al 7075-T6 sheet of $2 \mathrm{~mm}$ thick is provided. Then, the sketch of each specimen is drawn and given to a high-precision 2D CNC water jet cutting machine. Ultimately, the specimens are cut from the sheet. The failure experiments are carried out under displacement-control conditions with the speed of $1 \mathrm{~mm} / \mathrm{min}$ providing monotonic loading conditions. 


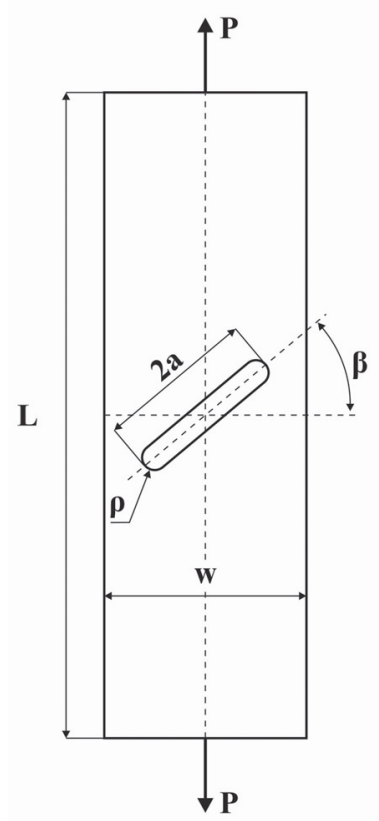

Fig. 2. The test specimen with its geometric parameters

\subsection{Test results}

Fig. 3 represents some of the U-notched Al 7075-T6 specimens before, during and after the failure tests.

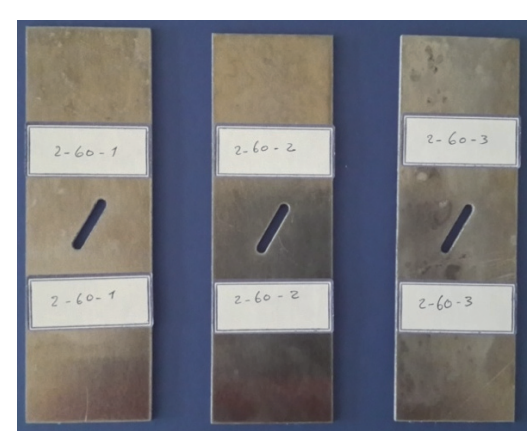

(a) before fracture

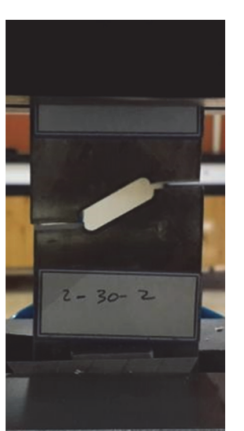

(b) during fracture

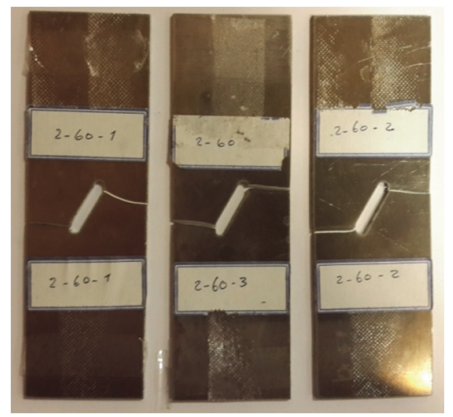

(c) after fracture

Fig. 3. Some of the U-notched Al 7075-T6 specimens before (a), during (b) and after (c) the failure tests

A large notch tip opening displacement (NTOD) is seen in Fig. 3b suggesting large plastic deformations around the notch. Such an opening displacement implies that the specimens fail by largescale yielding (LSY) regime. During the experiments, it was observed that a plastic zone initiates from the notch border and grows in large amount around the notch and fracture occurs abruptly so that the instance of crack initiation from the notch border could not be captured by the naked eye. The observations seem interesting and somewhat strange since large plastic deformations around the stress concentrators usually result in stable failure. The crack initiation and growth behaviors of a ductile material can be interpreted macroscopically using typical engineering stress-strain curve. Despite the strain to failure which is typically large for ductile materials, the strain at ultimate strength is a key parameter in determining the cracking behavior of material. A small strain interval between the ultimate and the final rupture points (like for the tested Al 7075-T6 alloy; see Fig. 1) means that crack nucleates in the ductile material by large plastic deformations and the material breaks abruptly by unstable crack growth. Conversely, if the strain interval becomes large, crack initiates quickly with relatively small 
plastic deformations and propagates slowly by large plastic deformations till final rupture. Such cracking behaviors can also be seen in ductile materials weakened by stress concentrators like cracks and notches. The main difference between the notched and un-notched specimens is that in an unnotched specimen, the entire cross-section experience plastic deformations while in a notched specimen, the plastic deformations are localized around the notch border as a result of the stress concentration. As mentioned at the beginning of this subsection, a large plastic region was observed at the notch tip vicinity at the onset of crack initiation from the notch border and abrupt fracture was recorded for the U-notched Al 7075-T6 specimens under mixed mode I/II loading, confirming the statement above about the cracking behavior of ductile materials. It is worth mentioning that, the fracture trajectory observed for the tested specimen is in agreement with the mixed mode fracture trajectory of similar specimens (Ayatollahi \& Aliha 2009). A sample load-displacement curve for a Unotched Al 7075-T6 specimen is shown in Fig. 4.

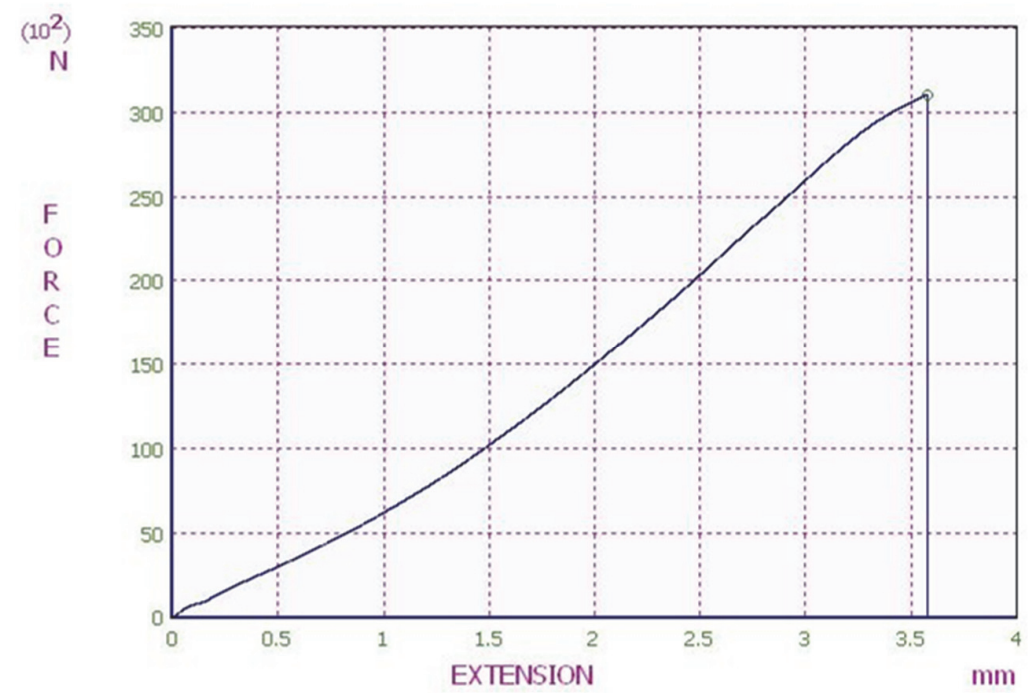

Fig. 4. A sample load-displacement curve for a U-notched Al 7075-T6 specimen

Two important points could be noted in Fig. 4. The first one is the existence of a clear but small nonlinear portion in the curve between the end of the proportional limit and the peak; and the second one is the sudden drop of the load from the peak to zero. The first one can be attributed to the stress concentration around the notch border (the plastic deformations are localized around the notch resulting in small nonlinear portion in the load-displacement curve of the notched specimen) and the second one to the cracking behavior of ductile materials with a small strain interval between the ultimate and final rupture points, which both were described above in the present subsection.

Table 3. The experimentally obtained LCC of the U-notched Al 7075-T6 thin sheets for various notch radii and different rotation angles.

\begin{tabular}{cccccc}
\hline$\beta($ deg. $)$ & $\rho(\mathrm{mm})$ & $\mathrm{P}_{1}(\mathrm{~N})$ & $\mathrm{P}_{2}(\mathrm{~N})$ & $\mathrm{P}_{3}(\mathrm{~N})$ & $\mathrm{P}_{\mathrm{av}}(\mathrm{N})$ \\
\hline 0 & 0.5 & 25424 & 24982 & 25700 & 25369 \\
0 & 1 & 27668 & 27083 & 28043 & 27598 \\
0 & 2 & 30236 & 30475 & 30041 & 30250 \\
30 & 0.5 & 29323 & 29268 & 28076 & 28889 \\
30 & 1 & 30706 & 31027 & 31347 & 31027 \\
30 & 2 & 33502 & 33179 & 33204 & 33295 \\
60 & 0.5 & 38767 & 38965 & 38038 & 38590 \\
60 & 1 & 39694 & 39782 & 39804 & 39760 \\
60 & 2 & 40062 & 40580 & 41036 & 40559 \\
\hline
\end{tabular}

It should be highlighted that the small nonlinear portion in the load-displacement curve of U-notched Al 7075-T6 specimens could not be resulted from a small-scale yielding (SSY) regime, because the 
curve of SSY is normally very similar to that of ideal brittle fracture which is usually linear till final fracture. The experimentally obtained LCC of the U-notched Al 7075-T6 thin sheets are presented in Table 3 for various notch radii and different rotation angles. In Table 3 , the parameter $P_{i}(i=1,2,3)$ denotes the LCC in the repeated tests and $\mathrm{P}_{\mathrm{av}}$. is the average of the three LCCs.

In the forthcoming sections, it is attempted to predict the experimental LCC of the specimens by linking the Equivalent Material Concept (EMC) to two well-known stress-based brittle fracture criteria.

\section{The Equivalent Material Concept}

Torabi (2012) proposed the Equivalent Material Concept (EMC) in order to use brittle fracture criteria for ductile failure prediction of notched members. By using EMC, a ductile material having valid $K$-based fracture toughness $\left(K_{I c}\right.$ or $\left.K_{c}\right)$ value is equated with a virtual brittle material having the same elastic modulus and fracture toughness, but various tensile strength. To compute the tensile strength of the equivalent material, it is assumed that the values of the tensile strain energy density (SED) till the ultimate point for the real ductile and virtual brittle materials are the same. A brief description of EMC is presented herein.

A sample engineering stress-strain curve is depicted in Fig. 5 for a typical ductile material.

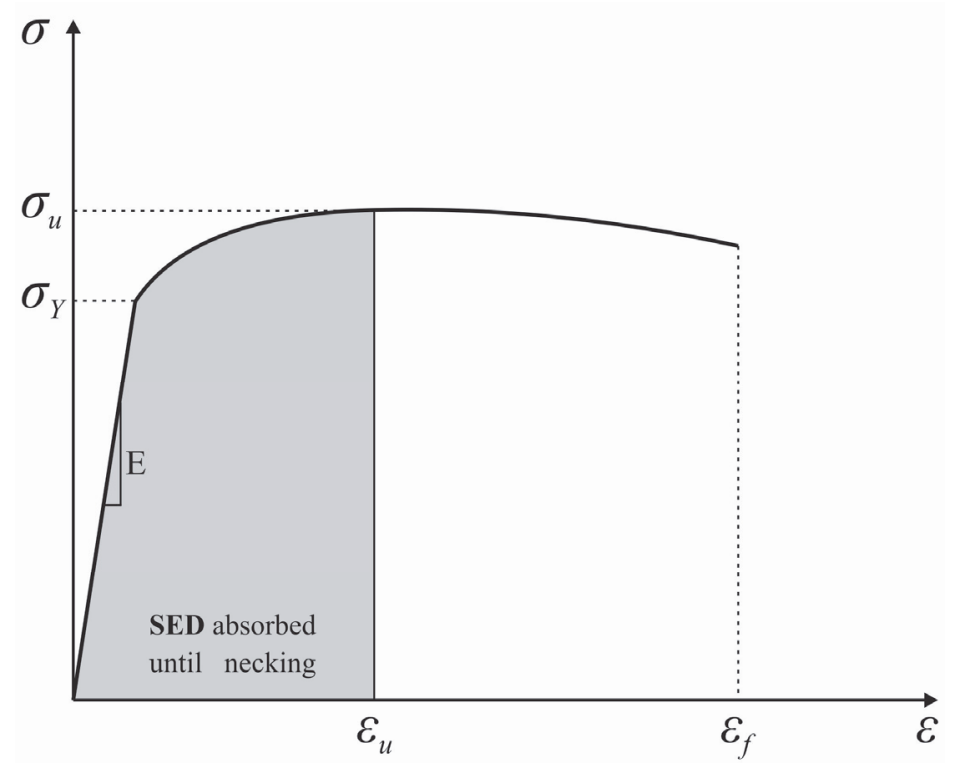

Fig. 5. A sample engineering stress-strain curve for a typical ductile material

The well-known power-law equation can be used to express the tensile stress-strain relationship in the plastic region. It is

$$
\sigma=K \varepsilon_{P}{ }^{n},
$$

where the parameters $\sigma, \varepsilon_{p}, K$, and $n$ in are the true stress, the true plastic strain, the strain-hardening coefficient, and the strain-hardening exponent, respectively. The SED, which is the area under the stress-strain curve, consists of elastic and plastic components. It can be written as follows:

$$
(\mathrm{SED})_{\mathrm{tot} .}=(\mathrm{SED})_{\mathrm{e}}+(\mathrm{SED})_{\mathrm{p}}=\frac{1}{2} \sigma_{\mathrm{Y}} \varepsilon_{\mathrm{Y}}+\int_{\varepsilon_{p}^{Y}}^{\varepsilon_{\mathrm{p}}} \sigma d \varepsilon_{\mathrm{p}} .
$$


In Eq. (2), $\sigma_{\mathrm{Y}}, \varepsilon_{\mathrm{Y}}$, and $\varepsilon_{p}^{Y}$ are the yield strength, the elastic strain at yield point, and the true plastic strain at yield point, respectively. Substituting Eq. (1) into Eq. (2) and considering that $\varepsilon_{Y}=\frac{\sigma_{Y}}{E}$ ( $E$ is the Young's modulus of material) we have:

$$
(\mathrm{SED})_{\text {tot. }}=\frac{\sigma_{\mathrm{Y}}{ }^{2}}{2 \mathrm{E}}+\int_{\varepsilon_{p}^{Y}}^{\varepsilon_{\mathrm{p}}} K \varepsilon_{P}{ }^{n} d \varepsilon_{\mathrm{p}} .
$$

Thus

$$
(\mathrm{SED})_{\mathrm{tot.}}=\frac{\sigma_{\mathrm{Y}}^{2}}{2 \mathrm{E}}+\frac{K}{n+1}\left[\left(\varepsilon_{P}\right)^{n+1}-\left(\varepsilon_{p}^{Y}\right)^{n+1}\right]
$$

The value of the parameter $\varepsilon_{p}^{Y}$ can simply be assumed to be equal to $0.002(0.2 \%$ offset $)$. Hence, Eq. 4 can be rewritten as

$$
(\mathrm{SED})_{\text {tot. }}=\frac{\sigma_{\mathrm{Y}}{ }^{2}}{2 \mathrm{E}}+\frac{K}{n+1}\left[\varepsilon_{P}{ }^{n+1}-(0.002)^{n+1}\right]
$$

It is clear that Eq. 5 gives the value of the total SED till any arbitrary point in the plastic region. In order to calculate the total SED required for the necking (i.e. the ultimate point in the stress-strain curve) to take place (see Fig. 5), $\varepsilon_{p}$ should be substituted in Eq. (5) with the true plastic strain at the

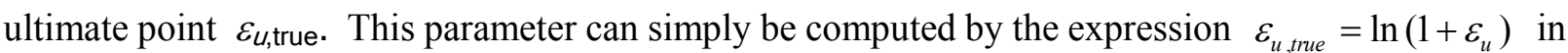
which $\varepsilon_{u}$ is the engineering plastic strain at the ultimate point. Therefore, the SED till necking is obtained to be

$$
(\mathrm{SED})_{\text {necking }}=\frac{\sigma_{\mathrm{Y}}{ }^{2}}{2 \mathrm{E}}+\frac{K}{n+1}\left[\varepsilon_{u, \text { true }}^{n+1}-(0.002)^{n+1}\right] \text {. }
$$

As mentioned earlier, the SED values absorbed by the real ductile and virtual brittle materials till crack initiation should be the same in accordance with EMC. For computing the tensile strength of the equivalent material, it is just required to formulate the SED for the equivalent material and equate it with Eq. (6).

A typical uni-axial stress-strain curve is represented in Fig. 6 for the equivalent material.

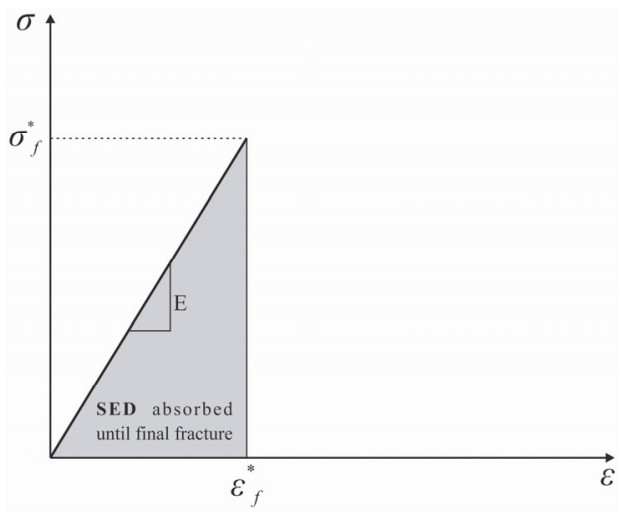

Fig. 6. A typical uni-axial stress-strain curve for the equivalent material 
The parameters $\varepsilon_{f}^{*}$ and $\sigma_{f}^{*}$ in Fig. 6 are the strain at crack initiation (i.e. at final fracture due to the brittleness of material) and the tensile strength of material, respectively. It is clear that the unit volume of the equivalent material requires the strain energy equal to that presented in Eq. (7) for the crack initiation to take place.

$$
(\mathrm{SED})_{\mathrm{EM}}=\frac{\sigma_{f}^{* 2}}{2 \mathrm{E}}
$$

According to EMC, Eq. (6) and Eq. (7) should be identical. Therefore

$$
\frac{\sigma_{f}^{* 2}}{2 \mathrm{E}}=\frac{\sigma_{\mathrm{Y}}^{2}}{2 \mathrm{E}}+\frac{K}{n+1}\left[\varepsilon_{u, t r u e}{ }^{n+1}-(0.002)^{n+1}\right]
$$

Extracting the tensile strength of the equivalent material $\sigma_{f}^{*}$ from Eq. (8) gives

$$
\sigma_{f}^{*}=\sqrt{\sigma_{\mathrm{Y}}^{2}+\frac{2 E K}{n+1}\left[\varepsilon_{u, t r u e}{ }^{n+1}-(0.002)^{n+1}\right]} \text {. }
$$

Now, we have a virtual brittle material with the fracture toughness of $K_{I c}$ (or $K_{c}$ ) and the tensile strength of $\sigma_{f}^{*}$ presented in Eq. (9). Fundamentally, brittle fracture criteria in the context of the LENFM can be used to provide predictions to the LCC of the U-notched specimens virtually made of the equivalent material. It is strongly expected that such predictions be in a good consistency with the experimentally-obtained LCC of the same U-notched specimens made of the real ductile material, since both materials absorb the same SED values till crack initiation at which the LCC is normally achieved.

In the next section, the U-notch maximum tangential stress (UMTS) and the U-notch mean-stress (UMS) brittle fracture criteria are formulated for the equivalent material by which the LCC of the Unotched Al 7075-T6 specimens is predicted under mixed mode I/II loading conditions.

\section{Formulation of the UMTS and UMS criteria for the equivalent material}

\subsection{The UMTS criterion}

A U-notch is schematically depicted in Fig. 7 together with its Cartesian and polar reference frames. The origin of the frames is located at the distance $r_{0}$ behind the notch tip on the notch bisector line.

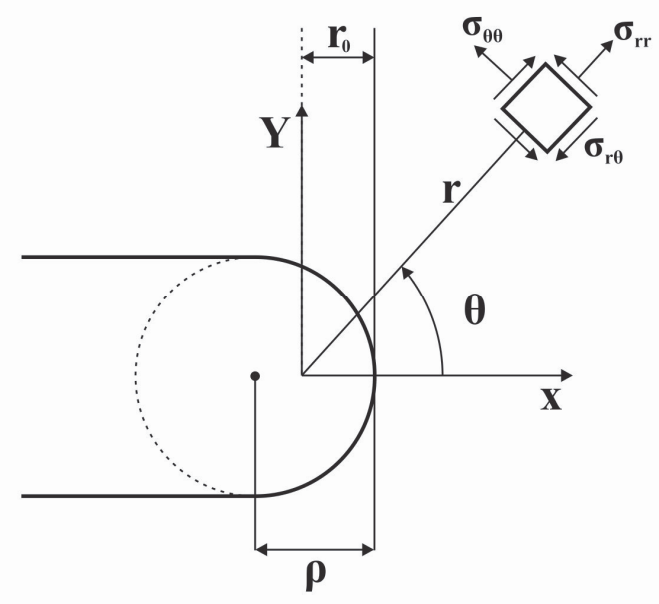

Fig. 7. A U-notch with its Cartesian and polar reference frames 
Creager and Paris (1967) have proposed some closed-form expressions for the elastic stress distributions around a blunt crack under combined tensile-shear loading. It has been shown in several references that such expressions could approximately be used also for U-shaped notches with a reasonable accuracy (see for instance the paper by Filippi et al. (2002). The tangential component of the stress field around a U-shaped notch can be given as follows (Creager \& Paris, 1967):

$$
\sigma_{\theta \theta}=\frac{1}{2 \sqrt{2 \pi r}}\left\{K_{I}^{U, \rho}\left[\left(\frac{3}{2}+\frac{\rho}{r}\right) \cos \frac{\theta}{2}+\frac{1}{2} \cos \frac{3 \theta}{2}\right]+K_{I I}^{U, \rho}\left[\left(\frac{3}{2}-\frac{\rho}{r}\right) \sin \frac{\theta}{2}+\frac{3}{2} \sin \frac{3 \theta}{2}\right]\right\}
$$

In Eq. (10), the parameters $K_{I}^{U, \rho}$ and $K_{I I}^{U, \rho}$ are the mode I and mode II notch stress intensity factors (NSIFs), respectively. Moreover, the parameters $\rho, r$ and $\theta$ denote the notch radius, the radial and the tangential components of the polar reference frame located at the distance $r_{0}=\rho / 2$ behind the U-notch tip, respectively.

The U-notch maximum tangential stress (UMTS) criterion proposes that brittle fracture occurs in a U-notched component when the tangential stress at a specified critical distance ahead of the notch border reaches to the material critical stress. To determine the point on the notch border from which crack initiates, one should search for the point experiences the maximum tangential stress. The maximum conditions can mathematically be written as

$$
\frac{\partial \sigma_{\theta \theta}}{\partial \theta}=0 \Rightarrow \theta=\theta_{0} \quad \frac{\partial^{2} \sigma_{\theta \theta}}{\partial \theta^{2}}<0
$$

In Eq. (11), the angle $\theta_{0}$ is called the fracture initiation angle (FIA). Note that solving Eq. (11) may result in positive and negative roots. To see which root maximizes the tangential stress, the sign of the second derivative of $\sigma_{\theta \theta}$ should be checked. It has been frequently shown in several references (Ayatollahi et al., 2011; Ayatollahi \& Torabi , 2010b, 2011; Torabi et al., 2014d; Torabi \& Pirhadi, 2015; Torabi \& Abedinasab, 2015a) that only the negative $\theta_{0}$ value satisfies the maximum conditions. Substituting Eq. (10) into Eq. (11) results in

$$
K_{I}^{U, \rho}\left[-\left(\frac{3}{4}+\frac{\rho}{2 r_{c, U}}\right) \sin \frac{\theta_{0}}{2}-\frac{3}{4} \sin \frac{3 \theta_{0}}{2}\right]+K_{I I}^{U, \rho}\left[\left(\frac{3}{4}-\frac{\rho}{2 r_{c, U}}\right) \cos \frac{\theta_{0}}{2}+\frac{9}{4} \cos \frac{3 \theta_{0}}{2}\right]=0
$$

In Eq. (10), the parameter $r_{c, U}$ is the U-notch critical distance. As seen in Fig. 8, two critical distances are defined for the U-notch which are denoted by $r_{c, U}$ and $r_{c}$ and measured from the origin of the reference frame and the notch tip, respectively. Note that only $r_{c}$ is physically meaningful because it lies on material.

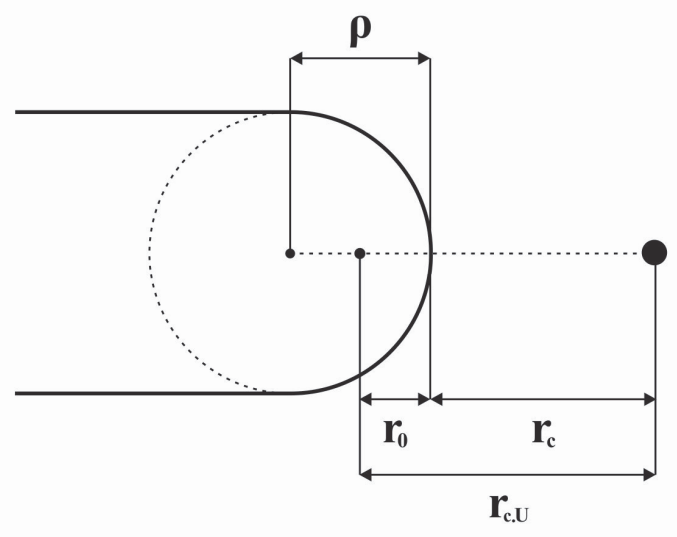

Fig. 8. A U-shaped notch with the critical distances of the UMTS criterion. 
Under pure mode I loading conditions, crack initiates at failure instance from the U-notch tip and grows along the notch bisector line, because of the symmetry in geometry and loading conditions. Hence, the fracture initiation angle (FIA) is expected to be zero. Under pure mode II loading conditions, $K_{I}^{U, \rho}$ is equal to zero and therefore, Eq. (12) can be reduced to

$$
\left(\frac{3}{4}-\frac{\rho}{2 r_{c, U}}\right) \cos \frac{\theta_{0}}{2}+\frac{9}{4} \cos \frac{3 \theta_{0}}{2}=0 \Rightarrow \theta_{0}=\theta_{0 I I}
$$

In Eq. (13), the parameter $\theta_{0 I I}$ denotes the mode II FIA. As mentioned earlier, according to the main hypothesis of the UMTS criterion, brittle fracture occurs for a U-notched member when the tangential stress at a specified critical distance ahead of the notch border attains the material critical stress $\sigma_{c}$. Thus, Eq. 10 can be rewritten at the onset of brittle fracture as follows:

$$
\sigma_{c}=\frac{1}{2 \sqrt{2 \pi r_{c, U}}}\left\{K_{I}^{U, \rho}\left[\left(\frac{3}{2}+\frac{\rho}{r_{c, U}}\right) \cos \frac{\theta_{0}}{2}+\frac{1}{2} \cos \frac{3 \theta_{0}}{2}\right]+K_{I I}^{U, \rho}\left[\left(\frac{3}{2}-\frac{\rho}{r_{c, U}}\right) \sin \frac{\theta_{0}}{2}+\frac{3}{2} \sin \frac{3 \theta_{0}}{2}\right]\right\} .
$$

The critical stress $\sigma_{c}$ for brittle materials has been successfully shown in the literature to be equal to the tensile strength of material (Ayatollahi \& Torabi, 2010a, 2010b, 2011; Torabi, 2013d; Ayatollahi et al., 2011; Torabi et al., 2013, 2014c, 2014d; Torabi \& Amininejad, 2015a, 2015b; Torabi \& Pirhadi 2015; Torabi \& Abedinasab, 2015a, 2015b). In order to eliminate $\sigma_{c}$ from Eq. 14 and present the failure equations in terms of the NSIFs, one can utilize a simple relationship that exists between $\sigma_{c}$ and the mode I notch fracture toughness (NFT) $K_{I c}^{U, \rho}$ (Torabi et al., 2013; Torabi, 2013d). It is

$$
\sigma_{c}=\frac{\left(2+\frac{\rho}{r_{c, U}}\right)}{2 \sqrt{2 \pi r_{c, U}}} K_{I c}^{U, \rho}
$$

Substituting Eq. (15) into Eq. (14) gives

$$
K_{I}^{U, \rho}\left[\left(\frac{3}{2}+\frac{\rho}{r_{c, U}}\right) \cos \frac{\theta_{0}}{2}+\frac{1}{2} \cos \frac{3 \theta_{0}}{2}\right]+K_{I I}^{U, \rho}\left[\left(\frac{3}{2}-\frac{\rho}{r_{c, U}}\right) \sin \frac{\theta_{0}}{2}+\frac{3}{2} \sin \frac{3 \theta_{0}}{2}\right]=\left(2+\frac{\rho}{r_{c, U}}\right) K_{I c}^{U, \rho}
$$

Note that unlike the plane-strain fracture toughness $\left(K_{I c}\right)$ which is a material property, the parameter $K_{I c}^{U, \rho}$ (i.e. the mode I NFT) depends on both the material properties and the U-notch tip radius. The mode I NFT can be obtained either theoretically by employing mode I brittle fracture criteria (Torabi et al., 2013; Torabi, 2013d) or experimentally by conducting mode I fracture tests on appropriate U-notched specimens (Torabi et al., 2013).

Let us assume that the values of the critical distance $r_{c, U}$ and the mode I NFT $K_{I c}^{U, \rho}$ are known. Now, one can divide both sides of Eqs. 12 and 16 by $K_{I c}^{U, \rho}$ and solve simultaneously these two equations for any values of $\theta_{0}$ between 0 and $\theta_{0 I I}$ to achieve a series of couple values $\left(K_{I}^{U, \rho} / K_{I c}^{U, \rho}, K_{I I}^{U, \rho} / K_{I c}^{U, \rho}\right.$ ). Each couple value denotes a point in the plane and connecting the entire points results in a fracture curve in which the variations of $K_{I I}^{U, \rho} / K_{I c}^{U, \rho}$ (vertical axis) are plotted versus $K_{I}^{U, \rho} / K_{I c}^{U, \rho}$ (horizontal axis) over the entire mixed mode I/II domain. An expression is presented in subsection 4.3 to calculate the values of the critical distance $r_{c, U}$ for the equivalent material weakened by a U-notch. Moreover, the experimental values of the mode I NFT $K_{I c}^{U, \rho}$ are presented in section 5 for the equivalent material. 


\subsection{The UMS criterion}

The U-notch mean-stress (UMS) criterion suggests that brittle fracture takes place in a notched component when the average value of the tangential stress over a specified critical distance ahead of the notch border attains the critical stress of material. The main difference between the UMTS and UMS criteria is that in the UMS criterion, the average value of the tangential stress over the critical distance should attain the critical stress rather than the tangential stress at a specified point ahead of the notch border. It is evident that determination of average of the tangential stress over the specified critical distance is the first step in formulating the UMS criterion. Therefore, it is tried herein to obtain a closed-form expression for the average stress distribution at the notch neighborhood. Similar to Fig. 8, Fig. 9 shows the critical distances of the UMS criterion, $d_{c, U}$ and $d_{c}$, which are measured from the reference frame origin and the notch tip, respectively. It is evident from Fig. 9 that $d_{c, U}=d_{c}+r_{0}$ where $r_{0}$ is equal to $\rho / 2$ for U-shaped notches (Torabi et al., 2013).

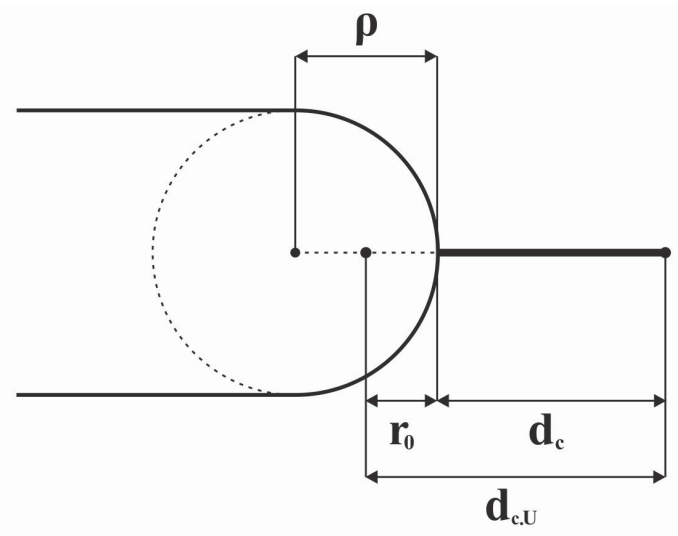

Fig. 9. A U-shaped notch with the critical distances of the UMS criterion

The average stress over the critical distance $d_{c}$ can be written as (Novozhilov, 1969; Seweryn $\&$ Lukaszewicz, 2002):

$$
\overline{\sigma_{\theta \theta}}=\frac{1}{d_{c}} \int_{r=r_{0}}^{r=d_{c, U}} \sigma_{\theta \theta} d r .
$$

Substituting Eq. (10) into Eq. (17) and integrating gives

$$
\begin{aligned}
& \overline{\sigma_{\theta \theta}}=\frac{K_{I}^{U, \rho}}{2 d_{c} \sqrt{2 \pi}}\left\{\left(3 \cos \frac{\theta}{2}+\cos \frac{3 \theta}{2}\right)\left(\sqrt{d_{c, U}}-\sqrt{r_{0}}\right)-2 \rho \cos \frac{\theta}{2}\left(\frac{1}{\sqrt{d_{c, U}}}-\frac{1}{\sqrt{r_{0}}}\right)\right\}+ \\
& \frac{K_{I I}^{U, \rho}}{2 d_{c} \sqrt{2 \pi}}\left\{\left(3 \sin \frac{\theta}{2}+3 \sin \frac{3 \theta}{2}\right)\left(\sqrt{d_{c, U}}-\sqrt{r_{0}}\right)+2 \rho \sin \frac{\theta}{2}\left(\frac{1}{\sqrt{d_{c, U}}}-\frac{1}{\sqrt{r_{0}}}\right)\right\}
\end{aligned}
$$
form:

The following auxiliary parameters are defined with the aim to present Eq. 18 in a more concise

$$
X=\sqrt{d_{c, U}}-\sqrt{r_{0}}, \quad Y=\frac{1}{\sqrt{d_{c, U}}}-\frac{1}{\sqrt{r_{0}}}
$$

By using Eq. (19), Eq. (18) can be rewritten as 
$\overline{\sigma_{\theta \theta}}=\frac{K_{I}^{U, \rho}}{2 d_{c} \sqrt{2 \pi}}\left\{\left(3 \cos \frac{\theta}{2}+\cos \frac{3 \theta}{2}\right) X-2 \rho \cos \frac{\theta}{2} Y\right\}+\frac{K_{I I}^{U, \rho}}{2 d_{c} \sqrt{2 \pi}}\left\{\left(3 \sin \frac{\theta}{2}+3 \sin \frac{3 \theta}{2}\right) X+2 \rho \sin \frac{\theta}{2} Y\right\}$.

Eq. (21) presents the maximum conditions for the average tangential stress.

$\frac{\partial \overline{\sigma_{\theta \theta}}}{\partial \theta}=0 \rightarrow \theta=\bar{\theta}_{0} \quad \frac{\partial^{2} \overline{\sigma_{\theta \theta}}}{\partial \theta^{2}}<0$

In Eq. (21), the angle $\overline{\theta_{0}}$ is called the fracture initiation angle (FIA) for the UMS criterion. Substituting Eq. (20) into Eq. (21) gives

$$
\begin{aligned}
& \frac{K_{I}^{U, \rho}}{2 d_{c} \sqrt{2 \pi}}\left(-\left(\frac{3}{2} \sin \frac{\bar{\theta}_{0}}{2}+\frac{3}{2} \sin \frac{3 \bar{\theta}_{0}}{2}\right) X+\rho Y \sin \frac{\bar{\theta}_{0}}{2}\right)+ \\
& \frac{K_{I I}^{U, \rho}}{2 d_{c} \sqrt{2 \pi}}\left(\left(\frac{3}{2} \cos \frac{\bar{\theta}_{0}}{2}+\frac{9}{2} \cos \frac{3 \bar{\theta}_{0}}{2}\right) X+\rho Y \cos \frac{\bar{\theta}_{0}}{2}\right)=0
\end{aligned}
$$

Under pure mode II loading conditions, the mode I NSIF $K_{I}^{U, \rho}$ becomes zero and hence, Eq. (22) is reduced to

$$
\left(\frac{3}{2} \cos \frac{\bar{\theta}_{0}}{2}+\frac{9}{2} \cos \frac{3 \bar{\theta}_{0}}{2}\right) X+\rho Y \cos \frac{\bar{\theta}_{0}}{2}=0 \Rightarrow \bar{\theta}_{0}=\overline{\theta_{0 I I}}
$$

The parameter $\overline{\theta_{0 I I}}$ in Eq. 23 is called the mode II FIA for the UMS criterion. According to UMS criterion, the mean stress $\overline{\sigma_{\theta \theta}}$ should attain the material critical stress $\sigma_{c}$ for brittle fracture to occur. Therefore

$$
\begin{aligned}
& \sigma_{c}=\frac{K_{I}^{U, \rho}}{2 d_{c} \sqrt{2 \pi}}\left\{\left(3 \cos \frac{\bar{\theta}_{0}}{2}+\cos \frac{3 \bar{\theta}_{0}}{2}\right) X-2 \rho Y \cos \frac{\bar{\theta}_{0}}{2}\right\}+ \\
& \frac{K_{I I}^{U, \rho}}{2 d_{c} \sqrt{2 \pi}}\left\{\left(3 \sin \frac{\bar{\theta}_{0}}{2}+3 \sin \frac{3 \bar{\theta}_{0}}{2}\right) X+2 \rho Y \sin \frac{\bar{\theta}_{0}}{2}\right\}
\end{aligned}
$$

To eliminate $\sigma_{c}$ from the formulas and present them in terms of the NSIFs, an explicit expression, similar to Eq. (15), is required. To reach to the expression, one can easily apply the mode I fracture requirements to Eq. (24) as follows:

$$
\begin{aligned}
& \overline{\theta_{0}}=0 \\
& K_{I}^{U, \rho}=K_{I c}^{U, \rho} \quad \Rightarrow \quad \sigma_{c}=\frac{K_{I c}^{U, \rho}}{2 \sqrt{2 \pi} d_{c}}(4 X-2 \rho Y)=\sqrt{\frac{2}{\pi d_{c, U}}} K_{I c}^{U, \rho} . \\
& K_{I I}^{U, \rho}=0
\end{aligned}
$$

Substituting Eq. (25) into Eq. (24) results in

$$
\frac{K_{I}^{U, \rho}}{K_{I c}^{U, \rho}} \frac{\sqrt{d_{c, U}}}{4 d_{c}}\left\{\left(3 \cos \frac{\overline{\theta_{0}}}{2}+\cos \frac{3 \overline{\theta_{0}}}{2}\right) X-2 \rho Y \cos \frac{\overline{\theta_{0}}}{2}\right\}+\frac{K_{I I}^{U, \rho}}{K_{I c}^{U, \rho}} \frac{\sqrt{d_{c, U}}}{4 d_{c}}\left\{\left(3 \sin \frac{\overline{\theta_{0}}}{2}+3 \sin \frac{3 \overline{\theta_{0}}}{2}\right) X+2 \rho Y \sin \frac{\overline{\theta_{0}}}{2}\right\}=1 .
$$

Dividing both sides of Eq. (22) by $K_{I c}^{U, \rho}$ gives

$$
\frac{K_{I}^{U, \rho}}{K_{I c}^{U, \rho}}\left(-\left(\frac{3}{2} \sin \frac{\bar{\theta}_{0}}{2}+\frac{3}{2} \sin \frac{3 \bar{\theta}_{0}}{2}\right) X+\rho Y \sin \frac{\bar{\theta}_{0}}{2}\right)+\frac{K_{I I}^{U, \rho}}{K_{I c}^{U, \rho}}\left(\left(\frac{3}{2} \cos \frac{\bar{\theta}_{0}}{2}+\frac{9}{2} \cos \frac{3 \bar{\theta}_{0}}{2}\right) X+\rho Y \cos \frac{\bar{\theta}_{0}}{2}\right)=0 .
$$


Eq. (26) and Eq. (27) form a linear system of equations in which the ratios $K_{I}^{U, \rho} / K_{I c}^{U, \rho}$ and $K_{I I}^{U, \rho} / K_{I c}^{U, \rho}$ are unknown. Assuming that the critical distances and the mode I NFT are known, the system can be solved for various values of $\overline{\theta_{0}}$ between zero and $\overline{\theta_{0 I I}}$, and the fracture curves of the UMS criterion can eventually be obtained in terms of $K_{I}^{U, \rho} / K_{I c}^{U, \rho}$ and $K_{I I}^{U, \rho} / K_{I c}^{U, \rho}$. In the next subsection, the critical distances of the UMTS and UMS criteria are formulated and the values of which are computed for the equivalent material.

\subsection{Computing the critical distances of UMTS and UMS criteria for the equivalent material}

As seen in subsections 4.1 and 4.2, the values of the critical distances are required to plot the fracture curves of the UMTS and UMS criteria. Since the critical distances of sharp crack for the MTS and MS criteria are normally assumed to be the material properties, they have been frequently used also for notches of different shapes (Ayatollahi \& Torabi, 2010a, 2010b, 2011; Torabi, 2013d; Ayatollahi et al., 2011; Torabi et al., 2013, 2014c, 2014d; Torabi \& Amininejad, 2015a, 2015b; Torabi \& Aliha 2013; Torabi \& Pirhadi 2015; Torabi \& Abedinasab, 2015a, 2015b,). For U-shaped notches, the critical distances can be written as

$$
r_{c, U}=r_{0}+r_{c}=\frac{\rho}{2}+\frac{1}{2 \pi}\left(\frac{K_{I c}}{\sigma_{c}}\right)^{2} ; d_{c, U}=r_{0}+d_{c}=\frac{\rho}{2}+\frac{2}{\pi}\left(\frac{K_{I c}}{\sigma_{c}}\right)^{2}
$$

In order to use Eq. (28) for the equivalent material, the critical stress $\sigma_{c}$ should be substituted with $\sigma_{f}^{*}$ (from Eq. (9)). Moreover, for thin components that do not satisfy the plane-strain fracture conditions (e.g. for thin Al 7075-T6 plates tested in the present study), the plane-strain fracture toughness $K_{I c}$ should be substituted with the fracture toughness $K_{c}$. Substituting the material properties from Table 2 into Eq. (9) results in $\sigma_{f}^{*}=1845 \mathrm{MPa}$. Subsequently, the critical distances $r_{c}$, and $d_{c}$ for the equivalent material are computed using Eq. (28) to be equal to $0.117 \mathrm{~mm}$ and $0.467 \mathrm{~mm}$, respectively.

It is attempted in the next section to convert the failure loads of the tested U-notched Al 7075-T6 specimens to the corresponding values of the critical normalized NSIFs in order to compare them with the fracture curves of the UMTS-EMC and UMS-EMC criteria.

\section{Results and discussion}

As presented in Section 4, the predictions of the UMTS-EMC and UMS-EMC criteria are in the form of the mixed mode I/II notch fracture toughness (NFT) which is assumed to be independent of the overall geometry of the U-notched member. In order to compare the experimentally obtained loadcarrying capacity (LCC) of the tested U-notched A1 7075-T6 thin plates with the theoretical predictions, it is necessary to convert the LCCs to the corresponding values of the critical normalized NSIFs. For this purpose, it is essential to create a finite element (FE) model for each U-notched plate and apply the experimentally obtained LCC presented in Table 3 together with appropriate boundary conditions to it. Once the linear-elastic tangential and in-plane shear stress distributions are resulted on the notch bisector line, the critical mode I and mode II NSIFs can be calculated for each U-notched plate virtually made of the equivalent material by using Eq. (29) and Eq. (30), respectively (Glinka, 1985; Glinka \& Newport, 1987; Lazzarin \& Filippi, 2006).

$$
\begin{aligned}
& K_{I}^{U, \rho}=\frac{\sqrt{\pi \rho}}{2} \sigma_{\theta \theta}\left(\frac{\rho}{2}, 0\right) \\
& K_{I I}^{U, \rho}=\operatorname{Lim}_{r \rightarrow \frac{\rho}{2}} \sqrt{2 \pi r} \frac{\sigma_{r \theta}(r, 0)}{\left(1-\frac{\rho}{2 r}\right)}
\end{aligned}
$$


Fig. 10 represents a sample mesh pattern for the U-notched specimen. As seen in Fig. 10, refined structured meshes are utilized at the notch vicinity (the dark area) because of high stress gradient.
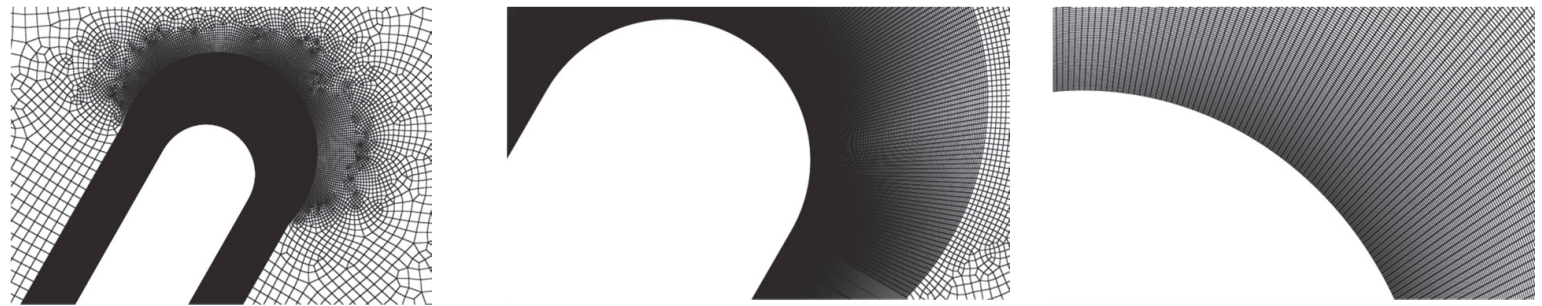

Fig. 10. A sample mesh pattern for the U-notched specimen

Table 4. Experimental values of the mode I NFT for the U-notched Al 7075-T6 specimens of various notch radii

$\rho(\mathrm{mm}) \quad 0.5 \quad 12$

Mean experimental

value of $K_{I c}^{U, \rho}$

73.1

78.5

85.1

$\left(\mathrm{MPa} \cdot \mathrm{m}^{0.5}\right)$

As mentioned earlier, the theoretical fracture curves are plotted in terms of the normalized NSIFs $K_{I}^{U, \rho} / K_{I c}^{U, \rho}$ and $K_{I I}^{U, \rho} / K_{I c}^{U, \rho}$. For comparing the experimental results with the theoretical predictions, the experimental values of the critical NSIFs computed by using Eqs. 29 and 30 should be divided by the mode I NFT $K_{I c}^{U, \rho}$. In order to calculate the experimental value of $K_{I c}^{U, \rho}$ for each U-notched specimen, first, the average of the three mode I failure loads presented in the last column of Table 3 (for $\beta=0$ ) should be applied to the FE model of the specimen and the corresponding tangential stress at the notch tip should be calculated. Then, the computed value is substituted into Eq. 29 instead of $\sigma_{\theta \theta}\left(\frac{\rho}{2}, 0\right)$ and the critical $K_{I}^{U, \rho}$ is calculated. Table 4 presents the experimental values of the mode I NFT $K_{I c}^{U, \rho}$ for the U-notched Al 7075-T6 specimens of various notch radii. Fig. 11 shows the fracture curves of the UMTS-EMC and UMS-EMC criteria together with the experimental results of the Unotched Al 7075-T6 specimens for different notch radii.
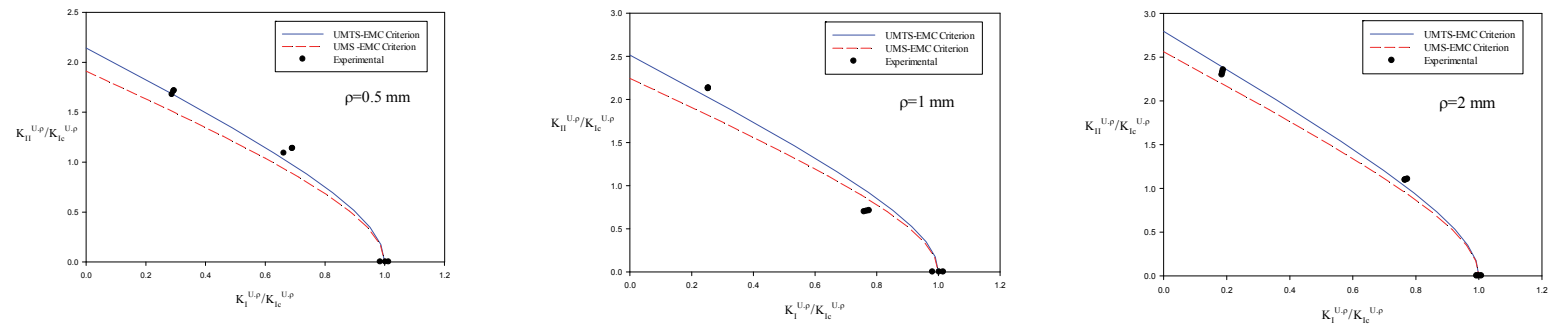

Fig. 11. The fracture curves of the UMTS-EMC and UMS-EMC criteria together with the experimental results of the U-notched Al 7075-T6 specimens for different notch radii

As can be seen in Fig. 11, the fracture curves of both UMTS-EMC and UMS-EMC criteria rise (i.e. the safe zone enhances) as the notch radius increases, because of decrease of the level of stress concentration. Moreover, the curves of both criteria for each value of the notch radius are very close together for mode I-dominant loading conditions. As the contribution of mode II deformations increases, the curves tend to diverge and finally, the maximum deviation is achieved under pure mode 
II loading. Fig. 11 also illustrates that the predictions of both criteria are accurate, although the UMTSEMC criterion gives generally better predictions to the experimental results. Furthermore, the fracture curve of the UMS-EMC criterion locates always under that of the UMTS-EMC criterion meaning that the UMS-EMC criterion is more conservative than the UMTS-EMC criterion. Therefore, considering good accuracy of both criteria, the UMS-EMC criterion may be preferred for engineering design purposes. A dimensionless parameter, called the effective notch fracture toughness ratio (ENFTR) $K_{\text {eff }}^{U, \rho}$, is defined herein for comparing the experimental and theoretical results quantitatively under mixed mode I/II loading conditions. It is

$$
K_{e f f}^{U, \rho}=\sqrt{\left(K_{I}^{U, \rho} / K_{I c}^{U, \rho}\right)^{2}+\left(K_{I I}^{U, \rho} / K_{I c}^{U, \rho}\right)^{2}} .
$$

It is obviously understood from Eq. (31) that $K_{\text {eff }}^{U, \rho}$ is the chord drawn from the reference frame origin to any point on the fracture curve or to any experimental data.

In Table 5, the theoretical values of the ENFTR are compared with the experimental ones for different notch radii and various rotation angles including the discrepancies. A total average discrepancy of about $4 \%$ is found between the predictions of the UMTS-EMC criterion and the mean experimental results. Such discrepancy is obtained to be equal to about $8 \%$ for the UMS-EMC criterion. The percent discrepancies demonstrate the success of both criteria in predicting mixed mode I/II NFT for the U-notched Al 7075-T6 thin plates.

It was mentioned in Section 2 of the present manuscript that large values of the NTOD are obtained at the onset of crack initiation from the U-notch border in Al 7075-T6 plates suggesting failure by largescale yielding (LSY) regime. To check to see if the elastic-plastic finite element (FE) analyses confirm the experimental observations, several FE analyses are carried out to determine the size of the plastic region around the notch border at the crack initiation instance. It is worth noting that the true material behavior shown in Fig. 1 is employed in the FE analyses and the mean LCC presented in the last column of Table 3 is applied to each FE model. Fig. 12 illustrates a distribution of the Von-Mises stress around the U-notch $\left(\rho=2 \mathrm{~mm}\right.$ and $\left.\beta=30^{\circ}\right)$ at crack initiation instance. It is clear in Fig. 12 that a large portion of the ligament experiences plastic deformations at failure instance confirming well the experimental observations about the existence of LSY failure regime for the U-notched Al 7075-T6 thin plates subjected to mixed mode loading.

Table 5. Comparison of the theoretical values of the ENFTR with the experimental ones for different notch radii and various rotation angles including the discrepancies

\begin{tabular}{|c|c|c|c|c|c|c|}
\hline \multicolumn{4}{|c|}{$\beta=30$ (deg.) } & \multicolumn{3}{|c|}{$\beta=60$ (deg.) } \\
\hline & $\rho=0.5(\mathrm{~mm})$ & $\rho=1$ & $\rho=2$ & $\rho=0.5$ & $\rho=1$ & $\rho=2$ \\
\hline $\begin{array}{l}\text { Mean experimental } \\
\text { results }\end{array}$ & 1.34 & 1.04 & 1.31 & 2.33 & 2.14 & 1.73 \\
\hline $\begin{array}{l}\text { UMTS-EMC } \\
\text { criterion }\end{array}$ & 1.31 & 1.13 & 1.25 & 2.39 & 2.06 & 1.72 \\
\hline UMS-EMC criterion & 1.28 & 1.11 & 1.19 & 2.21 & 1.89 & 1.58 \\
\hline $\begin{array}{c}\text { Mean } \\
\text { discrepancy of } \\
\text { UMTS-EMC } \\
\text { criterion (\%) } \\
\text { TOTAL: } \mathbf{3 . 8 \%} \\
\end{array}$ & 2.4 & 8.6 & 5.2 & 2.6 & 3.9 & 0.3 \\
\hline $\begin{array}{c}\text { Mean } \\
\text { discrepancy of } \\
\text { UMS-EMC } \\
\text { criterion (\%) } \\
\text { TOTAL: } 7.6 \% \\
\end{array}$ & 4.3 & 6.4 & 9.3 & 5.1 & 11.9 & 8.6 \\
\hline
\end{tabular}




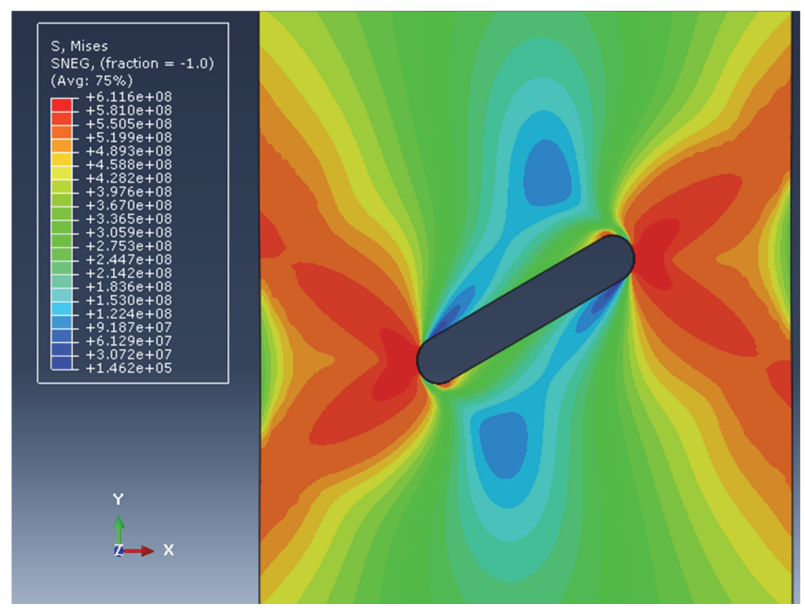

(a)

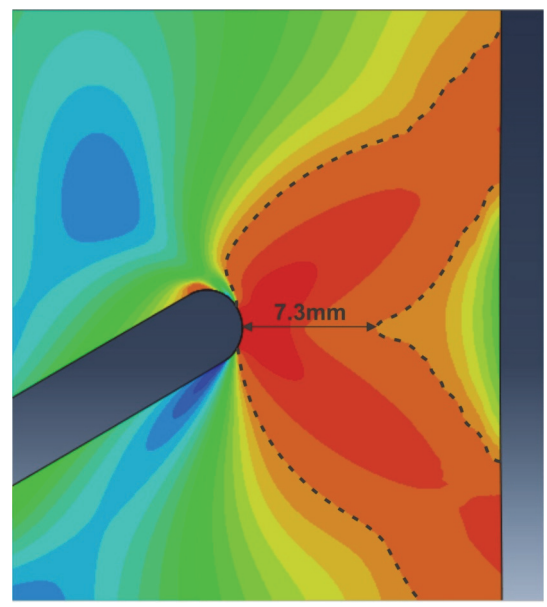

(b)

Fig. 12. A distribution of the Von-Mises stress around the U-notch $\left(\rho=2 \mathrm{~mm}\right.$ and $\left.\beta=30^{\circ}\right)$ at crack initiation instance; (a) a full view and (b) the plastic zone denoted by "---.".

Herein, the authors would like to highlight an important aspect of the aluminum alloys. In metal forming studies, the tensile stress-strain curve of aluminum alloys is normally modeled by the elasticperfectly plastic (EPP) behavior, because most of aluminum alloys do not exhibit considerable strainhardening in the plastic region. The EPP model is very suitable for metal forming purposes, since the energy absorbed by the material in the plastic zone is the sole important parameter. However, it is not a good model for fracture analyses, because it is not able to interpret the crack nucleation, crack propagation and the final rupture in aluminum components. As an instance, let us consider the failure of Al 7075-T6 thin plates evaluated in the present research and that of Al 6061-T6 plates reported by Torabi and Habibi (2015). It is evident that both aluminum alloys have the tensile stress-strain curves very close to the EPP behavior. However, the U-notched Al 7075-T6 plates exhibit unstable crack propagation behavior (see Section 2 of the present manuscript) and abrupt fracture; while the U-notched Al 6061-T6 plates reported by Torabi \& Habibi (2015) show stable crack growth and final rupture behaviors. This is because, in the standard tensile stress-strain curve, the ultimate point of Al 7075-T6 takes place at a strain value very close to the strain to failure; while that of Al 6061-T6 occurs at a rather low strain value. Accordingly, the real (not simplified) engineering stress-strain curve must be used to predict fracture behavior of aluminum alloys, particularly in the presence of stress raisers like U-notches.

From the present study, it is resulted that by linking the UMTS and UMS brittle fracture criteria to EMC, the mixed mode NFT of U-notched A1 7075-T6 thin plates could successfully be estimated under LSY regime with no need to perform elastic-plastic FE analysis. It is necessary to stress that the two brittle fracture criteria UMTS-EMC and UMS-EMC could be used to solely predict the LCC of ductile U-notched components and they are not able to estimate the trajectory of the crack emanating from the notch border or to determine the fracture plane etc., because the fracture behaviors of brittle and ductile materials are basically various.

\section{Conclusions}

The linear-elastic notch fracture mechanics (LENFM) was used in the present investigation for predicting the onset of crack initiation from U-notches in ductile components encountering large plastic deformations around the notch under mixed mode loading conditions. Fracture tests were performed on U-notched thin plates made of the aluminum alloy Al 7075-T6, which is a ductile material; for various mode mixity ratios and the load-carrying capacity (LCC) of the plates were experimentally measured. With the aim to avoid elastic-plastic finite element (FE) analyses and to predict ductile 
failure of U-notched plates by using brittle fracture criteria, the Equivalent Material Concept (EMC) was utilized to equate Al 7075-T6 with a virtual brittle material. The U-notch maximum tangential stress (UMTS) and U-notch mean stress (UMS) brittle fracture criteria were used to estimate the LCC of the U-notched plates virtually made of the equivalent material. A very good agreement was shown to exist between the theoretical results of the UMTS-EMC and UMS-EMC criteria and the experimental results. From both the FE analyses and the experimental observations, it was found that the ductile Unotched plates fail by large-scale yielding (LSY) regime. Therefore, it can be concluded that EMC could well be utilized in conjunction with the stress-based brittle fracture criteria for estimating crack initiation from the U-notch round border in Al 7075-T6 plates encountering LSY with no need of elastic-plastic analysis.

\section{Acknowledgement}

The authors would like to thank the anonymous referees for constructive comments on earlier version of this paper.

\section{References}

Aliha, M. R. M., \& Ayatollahi, M. R. (2013). Two-parameter fracture analysis of SCB rock specimen under mixed mode loading. Engineering Fracture Mechanics, 103, 115-123.

Aliha, M. R. M., Berto, F., Bahmani, A. Akhondi, Sh. \& Barnoush A. (2016). Fracture assessment of polymethylmetacrylate using sharp notched disc bend specimen under mixed mode I+III loading. Physical Mesomechanics, 19(4), Article in press.

Anderson, T.L. (1995). Fracture Mechanics: Fundamentals and Applications, 2nd ed., CRC Press LLC, Florida.

ASTM B646-12 (2012). Standard practice for fracture toughness testing of aluminum alloys, ASTM International, West Conshohocken, PA, United States.

ASTM E8 (2013). Standard test method for tension testing of metallic materials, ASTM International, West Conshohocken, PA, , United States.

ASTM E132-04 (2010). Standard test method for Poisson's ratio at room temperature, ASTM International, West Conshohocken, PA, 2010, United States.

Ayatollahi, M. R., \& Aliha, M. R. M. (2009). Analysis of a new specimen for mixed mode fracture tests on brittle materials. Engineering Fracture Mechanics, 76(11), 1563-1573.

Ayatollahi, M. R., Berto, F., \& Lazzarin, P. (2011a). Mixed mode brittle fracture of sharp and blunt Vnotches in polycrystalline graphite. Carbon, 49, 2465-2474.

Ayatollahi, M. R., Aliha, M. R. M., \& Saghafi, H. (2011b). An improved semi-circular bend specimen for investigating mixed mode brittle fracture. Engineering Fracture Mechanics, 78(1), 110-123.

Ayatollahi, M. R., \& Torabi, A. R. (2010a). Brittle fracture in rounded-tip V-shaped notches. Materials \& Design, 31, 60-67.

Ayatollahi, M. R., \& Torabi, A. R. (2010b). Investigation of mixed mode brittle fracture in roundedtip V-notched components. Engineering Fracture Mechanics, 77, 3087-3104.

Ayatollahi, M. R., \& Torabi, A. R. (2011). Experimental verification of RV-MTS model for fracture in soda-lime glass weakened by a V-notch. Journal of Mechanical Science and Technology, 25, 25292534.

Ayatollahi, M. R., Torabi, A. R., \& Azizi, P. (2011). Experimental and theoretical assessment of brittle fracture in engineering components containing a sharp V-notch. Experimental Mechanics, 51, 919932.

Berto, F., \& Ayatollahi, M. R. (2011). Fracture assessment of Brazilian disc specimens weakened by blunt V-notches under mixed mode loading by means of local energy. Materials \& Design, 32, 28582869.

Berto, F., \& Barati, E. (2011). Fracture assessment of U-notches under three point bending by means of local energy density. Materials \& Design, 32, 822-830. 
Berto, F., \& Lazzarin, P. (2009). A review of the volume-based strain energy density approach applied to V-notches and welded structures. Theoretical and Applied Fracture Mechanics, 52(3), 183-194.

Berto, F., \& Lazzarin, P. (2014). Recent developments in brittle and quasi-brittle failure assessment of engineering materials by means of local approaches. Materials Science and Engineering R, 75, 148.

Berto, F., Lazzarin, P., Gomez, F. J. \& Elices, M. (2007). Fracture assessment of U-notches under mixed mode loading: two procedures based on the equivalent local mode I concept. International Journal of Fracture, 148, 415-433.

Berto, F., Lazzarin, P., \& Marangon, C. (2012). Brittle fracture of U-notched graphite plates under mixed mode loading. Materials \& Design, 41, 421-432.

Carpinteri, A., Cornetti, P., Pugno, N., \& et al. (2008). A finite fracture mechanics approach to structures with sharp V-notches. Engineering Fracture Mechanics, 75, 1736-1752.

Cendon, D. A., Torabi, A. R., \& Elices, M. (2015). Fracture assessment of graphite V-notched and Unotched specimens by using the cohesive crack model. Fatigue and Fracture of Engineering Materials and Structures, 38, 563-573.

Cornetti, P., Mantic, V., \& Carpinteri, A. (2012). Finite Fracture Mechanics at elastic interfaces. International Journal of Solids and Structures, 49(7-8), 1022-1032.

Cornetti, P., Sapora, A., \& Carpinteri, A. (2014). T-stress effects on crack kinking in Finite Fracture Mechanics. Engineering Fracture Mechanics, 132, 169-176.

Creager, M., \& Paris, P. C. (1967). Elastic field equations for blunt cracks with reference to stress corrosion cracking. International Journal of Fracture Mechanics, 3, 247-252.

Glinka, G. (1985). Calculation of inelastic notch-tip strain-stress histories under cyclic loading. Engineering Fracture Mechanics, 22, 839-854.

Glinka, G., \& Newport, A. (1987). Universal features of elastic notch-tip stress fields. International Journal of Fatigue, 9, 143-150.

Gomez, F. J., \& Elices, M. (2003). A fracture criterion for sharp V-notched samples. International Journal of Fracture, 123, 163-175.

Gomez, F. J., Elices, M., Berto, F., \& Lazzarin, P. (2007). Local strain energy to assess the static failure of U-notches in plates under mixed mode loading. International Journal of Fracture, 145, 29-45.

Gomez, F. J., Elices, M., Berto, F., \& Lazzarin, P. (2009a). Fracture of V-notched specimens under mixed mode (I+II) loading in brittle materials. International Journal of Fracture, 159, 121-135.

Gomez, F. J., Elices, M., Berto, F., \& Lazzarin, P. (2009b). Fracture of U-notched specimens under mixed mode: experimental results and numerical predictions. Engineering Fracture Mechanics, 76, 236-249.

Gomez, F. J., Elices, M., \& Valiente, A. (2000). Cracking in PMMA containing U-shaped notches. Fatigue and Fracture of Engineering Materials and Structures, 23, 795-803.

Gomez, F. J., Guinea, G. V., \& Elices, M. (2006). Failure criteria for linear elastic materials with Unotches. International Journal of Fracture, 141, 99-113.

Filippi, S., Lazzarin, P., \& Tovo, R. (2002). Developments of some explicit formulas useful to describe elastic stress fields ahead of notches in plates. International Journal of Solids and Structures, 39, 4543-4565.

Lazzarin, P., \& Filippi, S. (2006). A generalized stress intensity factor to be applied to rounded Vshaped notches. International Journal of Solids and Structures, 43, 2461-2478.

Lazzarin, P., \& Zambardi, R. (2001). A finite-volume-energy based approach to predict the static and fatigue behavior of components with sharp V-shaped notches. International Journal of Fracture, 112, 275-298.

Madrazo, V., Cicero, S., \& Carrascal, I. A. (2012). On the Point Method and the Line Method notch effect predictions in Al 7075-T651. Engineering Fracture Mechanics, 79, 363-379.

Novozhilov, V. V. (1969). On necessary and sufficient criterion of brittle fracture. Prikladnaja Matematica i Mechanika, 33, 212-222.

Mirsayar, M. M., Aliha, M. R. M., \& Samaei, A. T. (2014). On fracture initiation angle near bi-material notches-Effects of first non-singular stress term. Engineering fracture mechanics, 119, 124-131. 
Sapora, A., Cornetti, P., \& Carpinteri, A. (2013). A Finite Fracture Mechanics approach to V-notched elements subjected to mixed-mode loading. Engineering Fracture Mechanics, 97, 216-226.

Sapora, A., Cornetti, P., \& Carpinteri, A., \& Firrao, D. (2015). An improved finite fracture mechanics approach to blunt V-notch brittle fracture mechanics: Experimental verification on ceramic, metallic and plastic materials. Theoretical and Applied Fracture Mechanics, 78, 20-24.

Saxena, A. (1998). Nonlinear fracture mechanics for engineers, CRC Press LLC, Florida.

Seweryn, A., \& Lukaszewicz, A. (2002). Verification of brittle fracture criteria for elements with Vshaped notches. Engineering Fracture Mechanics, 69, 1487-1510.

Susmel, L., \& Taylor, D. (2008a). On the use of the Theory of Critical Distances to predict static failures in ductile metallic materials containing different geometrical features. Engineering Fracture Mechanics, 75, 4410-4421.

Susmel, L., \& Taylor, D. (2008b). The theory of critical distances to predict static strength of notched brittle components subjected to mixed-mode loading. Engineering Fracture Mechanics, 75, 534550 .

Taylor, D. (2008). The theory of critical distances. Engineering Fracture Mechanics, 75(7), 1696-1705.

Torabi, A. R. (2012). Estimation of tensile load-bearing capacity of ductile metallic materials weakened by a V-notch: The equivalent material concept. Materials Science and Engineering A, 536, 249-255.

Torabi, A. R. (2013a). Ultimate bending strength evaluation of U-notched ductile steel samples under large-scale yielding conditions. International Journal of Fracture, 180, 261-268.

Torabi, A. R. (2013b). The Equivalent Material Concept: Application to failure of O-notches. Engineering Solid Mechanics, 1, 129-140.

Torabi, A. R. (2013c). On the use of the Equivalent Material Concept to predict tensile load-bearing capacity of ductile steel bolts containing V-shaped threads. Engineering Fracture Mechanics, 97, 136-147.

Torabi, A. R. (2013d). Fracture assessment of U-notched graphite plates under tension. International Journal of Fracture, 181, 285-292.

Torabi, A. R., \& Abedinasab, S. M. (2015a). Brittle fracture in key-hole notches under mixed mode loading: Experimental study and theoretical predictions. Engineering Fracture Mechanics, 134, 35 53.

Torabi, A. R., \& Abedinasab, S. M. (2015b). Mode II notch fracture toughness measurement for keyhole notches by the disk test. Journal of Strain Analysis for Engineering Design, 50(4), 264-275.

Torabi, A. R., \& Alaei, M. (2015). Mixed-mode ductile failure analysis of V-notched A1 7075-T6 thin sheets. Engineering Fracture Mechanics, 150, 70-95.

Torabi, A., \& Aliha, M.R.M. (2013). Determination of permissible defect size for solid axles loaded under fully-reversed rotating bending. Engineering Solid Mechanics, 1(1), 27-36.

Torabi, A. R., \& Amininejad, SH. (2015a). Brittle fracture in V-notches with end holes. International Journal of Damage Mechanics, 24(4), 529-545.

Torabi, A. R., \& Amininejad, SH. (2015b). Fracture assessment of VO-notches under mode II loading: Experiments and theories. Theoretical and Applied Fracture Mechanics, 75, 59-69.

Torabi, A. R., \& Berto, F. (2014a). Notch fracture toughness evaluation for a brittle graphite material. Materials Performance and Characterization, 3(3), 398-413.

Torabi, A. R., \& Berto, F. (2014b). Mixed mode fracture assessment of U-notched graphite Brazilian disk specimens by means of the local energy. Structural Engineering and Mechanics, 50(6), 723740.

Torabi, A. R., \& Berto, F. (2014c). Strain energy density to assess mode II fracture in U-notched disktype graphite plates. International Journal of Damage Mechanics, 23(7), 917-930.

Torabi, A. R., Campagnolo, A., \& Berto, F. (2014a). Tensile fracture analysis of key-hole notches by means of the Strain Energy Density. Strength of Materials, 48(2), 259-269.

Torabi, A. R., Campagnolo, A., \& Berto, F. (2014b). Mode II brittle fracture assessment of key-hole notches by means of the local energy. Journal of Testing and Evaluation, Article in press.

Torabi, A. R., Campagnolo, A., \& Berto, F. (2015a). Tensile fracture analysis of V-notches with end holes by means of the local energy. Physical Mesomechanics, 18(3), 194-202. 
Torabi, A. R., Campagnolo, A., \& Berto, F. (2015b). Experimental and theoretical investigation of brittle fracture in key-hole notches under mixed mode I/II loading. Acta Mechanica, 226, 23132322.

Torabi, A. R., Campagnolo, A., \& Berto, F. (2015c). Local strain energy density to predict mode II brittle fracture in Brazilian disk specimens weakened by $\mathrm{V}$-notches with end holes. Materials \& Design, 69, 22-29.

Torabi, A. R., Fakoor, M., \& Darbani, M. A. (2014c). Pure shear fracture study in a brittle graphite material containing a U-notch. International Journal of Damage Mechanics, 23(6), 839-854.

Torabi, A. R., Fakoor, M., \& Pirhadi, E. (2013). Tensile fracture in coarse-grained polycrystalline graphite weakened by a U-shaped notch. Engineering Fracture Mechanics, 111, 77-85.

Torabi, A. R., Fakoor, M., \& Pirhadi, E. (2014d). Fracture analysis of U-notched disc-type graphite specimens under mixed mode loading. International Journal of Solids and Structures, 51, 12871298.

Torabi, A. R., \& Habibi, R. (2015). Investigation of ductile rupture in U-notched Al 6061-T6 plates under mixed mode loading. Fatigue and Fracture of Engineering Materials and Structures. Article in press.

Torabi, A. R., Habibi, R., \& Mohammad Hosseini, B. (2015d). On the ability of the Equivalent Material Concept in predicting ductile failure of U-notches under moderate- and large-scale yielding conditions. Physical Mesomechanics, 18(4), 337-347.

Torabi, A. R., \& Pirhadi, E. (2015). Stress-based criteria for brittle fracture in key-hole notches under mixed mode loading. Europrean Journal of Mechanics A/Solids, 49, 1-12.

Vratnicaa, M., Pluvinage, G., Jodin, P., Cvijovic, Z., Rakin, M., Burzic, Z., \& Geric, K. (2013). Notch fracture toughness of high-strength Al alloys. Materials \& Design, 44, 303-310.

Weißgraeber, P., \& Becker, W. (2013). Finite Fracture Mechanics model for mixed mode fracture in adhesive joints. International Journal of Solids and Structures, 50(14-15), 2383-2394.

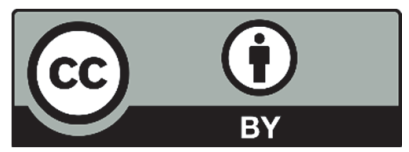

(C) 2016 by the authors; licensee Growing Science, Canada. This is an open access article distributed under the terms and conditions of the Creative Commons Attribution (CC-BY) license (http://creativecommons.org/licenses/by/4.0/). 